\title{
Characteristics of Abdominal Obesity in Persons With Spinal Cord Injury
}

\author{
Kwang Dong Kim, MD ${ }^{1}$, Hyung Seok Nam, MD ${ }^{1}$, Hyung Ik Shin, MD²
}

\author{
${ }^{1}$ Department of Rehabilitation Medicine, Seoul National University College of Medicine, Seoul; \\ ${ }^{2}$ Department of Rehabilitation Medicine, Seoul National University Bundang Hospital, Seongnam, Korea
}

Objective To investigate the characteristics of community-dwelling spinal cord injury (SCI) persons with obesity, including diet, socioeconomic factors, weight reduction method, and frequency of body weight and abdominal circumference measurements.

Methods We developed a questionnaire based on 'the Fourth Korea National Health and Nutrition Examination Survey, 2009'. A total of 371 community-dwelling SCI persons were enrolled in this study. Inclusion criteria were SCI persons older than 20 years with more than 1 year elapsed since the injury. Trained investigators visited SCI persons' home to complete the questionnaire and measure abdominal obesity (AO) as defined by the waist circumference.

Results Prevalence of AO was $29.2 \%$ in SCI persons and $27.4 \%$ in the general population (GP), showing no significant difference. Education showed correlation with AO in both SCI persons and the GP. The injury level, type of injury and income did not show any correlation with AO in SCI persons. Only $28.8 \%$ and $48.8 \%$ of SCI persons measured their waist circumference and body weight within the past year, respectively. Also, SCI persons with AO thought that their body was less obese compared to persons with AO in the GP ( $<<0.001)$. The method of weight reduction was diet modification in $53.6 \%$ of SCI persons with AO, which was higher than $37.1 \%$ of persons with $\mathrm{AO}$ in the GP.

Conclusion In SCI persons, obesity perception as well as socioeconomic factors correlated with AO, but these were not relevant factors in the GP. Therefore, development of a specific and intensive weight control program for SCI persons is necessary.

Keywords Spinal cord injuries, Abdominal obesity, Exercise, Health behavior, Socioeconomic factors

Received July 2, 2012; Accepted November 7, 2012

Corresponding author: Hyung Ik Shin

Department of Rehabilitation Medicine, Seoul National University Bundang Hospital, 82 Gumi-ro 173beon-gil, Bundang-gu, Seongnam 463-707, Korea

Tel: +82-31-787-7733, Fax: +82-31-787-4056, E-mail: hyungik1@snu.ac.kr

(c) This is an open-access article distributed under the terms of the Creative Commons Attribution Non-Commercial License (http://creativecommons. org/licenses/by-nc/3.0) which permits unrestricted noncommercial use, distribution, and reproduction in any medium, provided the original work is properly cited.

Copyright $\odot 2013$ by Korean Academy of Rehabilitation Medicine

\section{INTRODUCTION}

Obesity is known as an important factor of chronic diseases such as metabolic syndrome [1-4], and obesity itself also has considerable effects on life satisfaction and quality of life [5]. Spinal cord injury (SCI) patients are especially vulnerable to obesity and chronic diseases due to decreased physical activity and changes in their diet [6,7]. As medical care continues to improve for SCI patients, mortality related with decreased vital capacity, impaired 
sputum expectoration, pneumonia, kidney injury due to vesicoureteral reflux, is decreasing. The major causes of death in this population are stroke and cardiovascular diseases, as in the general population (GP). DeVivo et al. [8] reported that in the 1990s compared with the 1970s, complications involving the urinary system significantly decreased whereas cardiovascular and malignancy related mortality considerably increased in chronic SCI patients. Garshick et al. [9] indicated that persons with SCI become more vulnerable to chronic diseases such as cardiovascular diseases, and Orakzai et al. [10] demonstrated that the prevalence of coronary artery calcification was higher in the SCI group than in the GP even after compensating for age, sex, ethnicity, and other risk factors of coronary disease. Bauman and Spungen [11] reported that $65 \%$ of asymptomatic subjects with SCI were found to have coronary artery occlusion by a nuclear medicine study in a cohort study consisting of paraplegia patients with a mean age of 52 .

Advances in medical practice and technology have extended the lifespan of SCI patients, but if they suffer from chronic diseases such as cardiovascular diseases, the quality of life declines and the purpose of extending their life would be reduced. In this sense, the control of obesity, which is an important risk factor of chronic diseases, is very important and therefore lifestyle modification is necessary. However, guidelines for exercise or diet modification for SCI patients are not definitely established in Korea, and also primary data are insufficient.

In this study, we measured the abdominal circumference of SCI patients as abdominal circumference is a good indicator of obesity, and investigated their physical activities, behaviors to improve their health, and socioeconomic factors to compare them with those of the GP. From these data, we aimed to analyze the characteristics of the health behavior of SCI patients and provide primary data to enhance their health.

\section{MATERIALS AND METHODS}

Three investigators were trained for 8 hours, and validity was checked after 20 examples of preliminary investigations. The investigator visited the subjects' home and conducted questionnaires, and also measured their abdominal circumference.

\section{Subjects}

The study was conducted on members of Korea Spinal Cord Injury Association as they volunteered to participate in the survey. A total of 371 subjects were registered for the study. Inclusion criteria were more than age of 20 , with the elapse of more than 1 year since the onset of the SCI. For the control group, subjects were selected from the GP of the Korea National Health and Nutrition Examination Survey (KNHNES) 2009.

\section{Waist circumference measure}

Measurement methods for abdominal circumference were identical with the methods used in the KNHNES. In the right and left mid-axillary line, the lower margin of the 12th rib and upper margin of the iliac crest were marked with a pen, and the distance between the two points were measured to the nearest tenth of a centimeter during expiration. The subjects were categorized as obese if their abdominal circumference exceeded $90 \mathrm{~cm}$ for men and $85 \mathrm{~cm}$ for women, as previous studies have recommended [12].

\section{Questionnaire}

Survey items were selected from the KNHNES 2009 questionnaire, and these were related to obesity or the health behaviors of SCI patients (Appendix 1). They included socioeconomic factors such as age, sex, education level, and marriage status before and after the injury, occupation, housemate characteristics, income, and characteristics of SCI such as the degree of disability, level of injury, cause of injury, and extent of injury. For the physical activity level, the subjects were asked how many days a week they were exercising hard or to the degree that dyspnea occurs. Similarly, the number of days during a week that they carried out stretching or free gymnastics, and the number of days that they did push-ups, sit-ups or dumbbell exercises were also investigated. Considering the characteristics of SCI, suggested examples of physical activities included wheelchair basketball, swimming, and moving fast with the wheelchair.

For the obesity and weight control category, subjects were asked about their body image, whether they had measured their weight or abdominal circumference within the past year, their height and weight from memory, and efforts to control weight such as diet modification, exercise and medication adjustment. 
Kwang Dong Kim, et al.

Table 1. Comparison between general population (GP) and spinal cord injury (SCI) patients

\begin{tabular}{|c|c|c|c|}
\hline & GP & SCI & p-value \\
\hline Age & $49.3 \pm 16.6$ & $44.8 \pm 9.6$ & $<0.001^{*}$ \\
\hline Male & $49.0 \pm 16.4$ & $45.0 \pm 9.3$ & $<0.001^{*}$ \\
\hline Female & $49.5 \pm 16.7$ & $44.2 \pm 10.9$ & $<0.001^{*}$ \\
\hline \multicolumn{4}{|l|}{ Sex } \\
\hline Male & $3,411(43.7)$ & $308(83.0)$ & \\
\hline Female & $4,387(56.3)$ & $63(17.0)$ & \\
\hline \multicolumn{4}{|l|}{ Level of injury } \\
\hline Cervical & & $144(38.8)$ & \\
\hline Thoracic & & $187(50.4)$ & \\
\hline Lumbosacral & & $28(7.5)$ & \\
\hline Unknown & & $10(2.7)$ & \\
\hline Missing value & & $2(0.5)$ & \\
\hline Total & & 371 & \\
\hline \multicolumn{4}{|l|}{ Cause of injury } \\
\hline Trauma & & $335(90.3)$ & \\
\hline Disease & & $29(7.8)$ & \\
\hline Unknown & & $1(0.3)$ & \\
\hline Missing value & & $6(1.6)$ & \\
\hline Total & & 371 & \\
\hline \multicolumn{4}{|l|}{ Waist circumference } \\
\hline Male & $84.2 \pm 9.0$ & $85.5 \pm 9.1$ & $0.044^{*}$ \\
\hline Female & $78.8 \pm 10.0$ & $77.3 \pm 9.5$ & 0.280 \\
\hline \multicolumn{4}{|l|}{ Abdominal obesity (AO) } \\
\hline Male & 886 (27.6) & $72(30.6)$ & 0.319 \\
\hline Female & $1,150(27.3)$ & $12(22.6)$ & 0.454 \\
\hline Total & $2,036(27.4)$ & $84(29.2)$ & 0.512 \\
\hline Subjective body image in AO persons & & & $<0.001^{*}$ \\
\hline Very thin & $17(0.8)$ & $0(0)$ & \\
\hline Thin & $52(2.6)$ & $6(7.1)$ & \\
\hline Average & $402(19.7)$ & $35(41.7)$ & \\
\hline Fat & $1,027(50.4)$ & $32(38.1)$ & \\
\hline Very fat & 535 (26.3) & $10(11.9)$ & \\
\hline Unknown & $3(0.2)$ & $1(1.2)$ & \\
\hline Total & $2,036(100)$ & $84(100)$ & \\
\hline \multicolumn{4}{|l|}{ Exercise in AO persons } \\
\hline Heavy exercise & $600(29.5)$ & $52(61.9)$ & $<0.001^{*}$ \\
\hline Heavy exercise more than 3 days & $310(15.2)$ & $42(50.0)$ & $<0.001^{*}$ \\
\hline Muscle strengthening exercise & $428(21.0)$ & $35(41.7)$ & $<0.001^{*}$ \\
\hline Muscle strengthening exercise more than 2 days & $340(16.7)$ & $30(35.7)$ & $<0.001^{*}$ \\
\hline Education in AO persons & & & $<0.001^{*}$ \\
\hline Less than elementary school & $775(38.1)$ & $12(14.3)$ & \\
\hline Middle school to high school & $859(42.2)$ & $56(66.7)$ & \\
\hline College or more & $392(19.3)$ & $16(19.0)$ & \\
\hline Missing value & $10(0.5)$ & $0(0)$ & \\
\hline Total & 2,036 & 84 & \\
\hline
\end{tabular}

Values are presented as mean \pm standard deviation or number (\%).

${ }^{*} \mathrm{p}<0.05$. 


\section{Statistical analysis}

Descriptive statistical analyses were done for social demographic characteristics and extent of obesity, and the level of physical activity. Chi-square analyses were done to analyze the difference of obesity, exercise, efforts for weight control and socioeconomic characteristics between the GP and SCI patients. Binary logistic regression was done for age, education level, monthly income, and duration of time since the injury. p-values of less than 0.05 were considered significant. All statistical analyses were carried out with SPSS ver. 17.0 (SPSS Inc., Chicago, IL, USA). This study was approved by the Institutional Review Board of Seoul National University Bundang Hospital.

\section{RESULTS}

\section{Demographic data}

Questionnaires of 371 subjects from the SCI group were analysed. The SCI group consisted of 308 (83\%) men and $63(17 \%)$ women and their mean age was 44.8 years. The GP group consisted of 3,411 men (43.7\%) and 4,387 women $(56.3 \%)$ and their mean age was 49.3 years (Table 1 ).

In the SCI group, there were 76 (20.5\%) complete tetraplegia patients, 148 (39.9\%) complete paraplegia patients, $63(17.0 \%)$ incomplete tetraplegia patients, and 76 (20.5\%) incomplete paraplegia patients. Average time after onset of injury was $13.7 \pm 8.5$ years. In the level of injury, cervical, thoracic, and lumbosacral level consisted of 144 (38.8\%), 187 (50.4\%), and 28 (7.5\%) subjects, respectively. Three hundred and thirty-five (90.3\%) subjects had traumatic injury and 29 (7.8\%) subjects had SCI due to medical disease. One subject did not confirm the cause of injury.

\section{Abdominal circumference and abdominal obesity}

The Korean Society for the Study of Obesity has defined abdominal obesity as an abdominal circumference over $90 \mathrm{~cm}$ in males, and over $85 \mathrm{~cm}$ in females. According to this criteria, the rate of obesity in the SCI group was $29.2 \%$ and $27.4 \%$ in the GP, showing no significant difference between the two groups ( $\mathrm{p}=0.51$ ) (Table 1$)$. The obesity rate was similar to other previous studies $[13,14]$. In males, obesity rates in the SCI group and GP group were $30.6 \%$ and $27.6 \%$, respectively, with no significant difference between the groups ( $\mathrm{p}=0.319)$ (Table 1$)$. In females, obesity rates in the SCI group and GP group were $22.6 \%$ and $27.3 \%$, respectively $(\mathrm{p}=0.454)$ (Table 1$)$.

In the SCI group, obesity rates in complete tetraplegia, incomplete tetraplegia, complete paraplegia, incomplete paraplegia were $23.8 \%, 27.1 \%, 37.8 \%$, and $18.3 \%$, respectively. The complete paraplegia group had a higher obesity rate compared to the incomplete paraplegia group $(\mathrm{p}=0.008)$ (Table 2). Monthly income and abdominal obesity rate were independent of each other $(p=0.388)$ but the abdominal obesity rate was dependent on education level ( $p=0.002)$ (Table 2). Odds of abdominal obesity in SCI persons with a final education level between middle and high school was 0.487 compared to SCI persons with a final education level under elementary school. SCI persons who had entered college had odds of 0.211 for abdominal obesity, compared to those with a final education level under elementary school. Also in the SCI group, odds for abdominal obesity increased by 1.031 as each year passed $(p=0.046)$.

\section{Exercises}

SCI persons with abdominal obesity (61.9\%) had higher rates of exercising up to the degree that induced dyspnea at least once a week compared to persons with abdominal obesity in the GP $(29.5 \%, \mathrm{p}<0.001)$ (Table 1$)$. For rates of exercise to the degree that induced dyspnea at least three times a week, SCI persons with abdominal obesity (50.0\%) had higher rates than persons with abdominal obesity in the GP $(15.2 \%, \mathrm{p}<0.001)$ (Table 1$)$.

In the SCI group, the rate of exercising at least once a week up to the degree that induced dyspnea was $61.9 \%$ in the abdominal obesity group, which was not significantly different to the normal abdominal circumference group (65.2\%, $\mathrm{p}=0.596$ ) (Table 2). For the rates of exercise at least three times a week up to the degree that induced dyspnea, the abdominal obesity group (50.0\%) and normal abdominal circumference group (47.5\%) did not show significant difference $(\mathrm{p}=0.705)$ (Table 2).

In SCI persons with abdominal obesity, $41.7 \%$ replied that they were carrying out resistive exercises more than once a week, while it was $52.9 \%$ in the normal abdominal circumference group. There was no significant difference between the two groups $(\mathrm{p}=0.082)$ (Table 2). For carrying out resistive exercises more than twice a week, it was $35.7 \%$ and $45.6 \%$ in the abdominal obesity and normal abdominal circumference groups, respectively, showing no significant difference ( $\mathrm{p}=0.124)$ (Table 2). 
Table 2. Subgroup analysis: NAC persons with SCI versus abdominal obesity persons with SCI

\begin{tabular}{|lccc}
\hline & NAC & AO & p-value \\
\hline Age & $44.0 \pm 9.6$ & $48.6 \pm 9.4$ & 0.481 \\
\hline Sex & & & 0.247 \\
\hline Male & $163(69.4)$ & $72(30.6)$ & \\
\hline Female & $41(77.4)$ & $12(22.6)$ & 0.392 \\
\hline Time to injury & $13.1 \pm 8.3$ & $15.3 \pm 8.3$ & $0.002^{*}$ \\
\hline Education & & & \\
\hline Less than elementary school & $12(5.9)$ & $12(14.3)$ & \\
\hline Middle to high school & $115(56.7)$ & $56(66.7)$ & \\
\hline College or more & $76(37.4)$ & $16(19.0)$ & \\
\hline Total & 203 & 84 & \\
\hline Type of SCI & $18(76.2)$ & $15(23.8)$ & \\
\hline Complete tetraplegia & $35(72.9)$ & $13(27.1)$ & \\
\hline Incomplete tetraplegia & $69(81.7)$ & $42(37.8)$ & \\
\hline Complete paraplegia & $49(81.7)$ & $11(18.3)$ & \\
\hline Incomplete paraplegia & 2 & 3 & \\
\hline Unknown & 203 & 84 & \\
\hline Total & & & \\
\hline Exercise & $133(65.2)$ & $52(61.9)$ & 0.596 \\
\hline Heavy exercise & $97(47.5)$ & $42(50.0)$ & 0.705 \\
\hline Heavy exercise more than 3 days & $108(52.9)$ & $35(41.7)$ & 0.082 \\
\hline Muscle strengthening exercise & $93(45.6)$ & $30(35.7)$ & 0.124 \\
\hline Muscle strengthening exercise more than 2 days & & \\
\hline
\end{tabular}

Values are presented as mean \pm standard deviation or number (\%).

NAC, normal abdominal circumference; AO, abdominal obesity; SCI, spinal cord injury.

${ }^{*} \mathrm{p}<0.05$.

\section{Perception of abdominal obesity}

In the SCI group, only $28.8 \%$ of the patients replied that they had measured their abdominal circumference during the last year. Within this group, persons with normal abdominal circumference $(47.7 \%)$ measured their abdominal circumference significantly more often than persons with abdominal obesity $(21.0 \%, \mathrm{p}=0.026)$. For body weight measurement, $48.8 \%$ of the SCI group replied that they had checked their body weight during the last year. Persons with abdominal obesity (47.6\%) and normal abdominal circumference (54.9\%) did not show significant difference.

Of the persons with abdominal obesity in the GP, $76.7 \%$ (mild obesity $50.4 \%$, severe obesity $26.3 \%$ ) perceived themselves to be obese, while $50.0 \%$ (mild obesity $38.1 \%$, severe obesity $11.9 \%$ ) of the persons with abdominal obesity in the SCI group perceived themselves to be obese. The rate of obesity perception was significantly lower in the SCI group $(\mathrm{p}<0.001)$ (Table 1$)$.

\section{Efforts for weight control}

For the question asking about methods of body weight reduction or weight maintenance used within the last year, $47.2 \%$ of the GP group and $46.4 \%$ of the SCI group replied they used "exercise" ( $p=0.897)$ (Table 3). Medication was used in $6.8 \%$ of the GP group and $11.9 \%$ of the SCI group $(\mathrm{p}=0.074)$. However, dietary methods were used in $37.1 \%$ of the GP group and $53.6 \%$ of the SCI group, showing a significantly higher rate in the SCI group ( $\mathrm{p}<0.002)$ (Table 3$)$.

Within the SCI group, there were no differences in weight control methods between tetraplegia and paraplegia, and also between complete injury and incomplete injury, for all specific methods such as exercises, dietary modification, and medication (Table 4). 
Table 3. Effort for weight control in obese persons

\begin{tabular}{lccc}
\hline & GP & SCI & p-value \\
\hline $\begin{array}{l}\text { Effort for body weight } \\
\text { control }\end{array}$ & & & $<0.001^{*}$ \\
\hline $\begin{array}{l}\text { Try to reduce } \\
\text { Try to maintain }\end{array}$ & $1,099(54.1)$ & $44(52.4)$ & \\
Try to gain & $9(8.2)$ & $18(21.4)$ & \\
No effort & $759(37.3)$ & $21(25.0)$ & \\
Total & 2,033 & 84 & \\
$\begin{array}{l}\text { Method of weight } \\
\text { control }\end{array}$ & & & \\
Exercise & $960(47.2)$ & $39(46.4)$ & 0.897 \\
\hline Medication & $139(6.8)$ & $10(11.9)$ & 0.074 \\
\hline Diet modification & $756(37.1)$ & $45(53.6)$ & $0.002^{*}$ \\
\hline Total & 1,845 & 84 & \\
\hline
\end{tabular}

Values are presented as number (\%).

GP, general population; SCI, spinal cord injury. ${ }^{*} \mathrm{p}<0.05$.

\section{DISCUSSION}

\section{Abdominal circumference as an index for obesity}

National Institutes of Health obesity guidelines suggest body mass index (BMI) and abdominal circumference should be used as indicators for body fat since the absolute body fat amount is difficult to measure. Additionally, they state that the abdominal circumference reflects the risk of secondary complications due to excessive body fat accumulation better than BMI.

The Korean Society for the Study of Obesity defines "obesity" as BMI being $25 \mathrm{~kg} / \mathrm{m}^{2}$ or more, and "abdominal obesity" as an abdominal circumference greater than 90 $\mathrm{cm}$ in men and $85 \mathrm{~cm}$ in women.

McDonald et al. [15] reported that SCI patients have more body fat than the GP having the same BMI value in a study using dual energy X-ray absorptiometry. Edwards et al. [16] revealed that SCI patients have three times more visceral fat tissue than the GP with the same abdominal circumference, suggesting that serial measurement of the abdominal circumference in SCI patients is helpful. Buchholz et al. [17] and Eriks-Hoogland et al. [18] also insisted that abdominal circumference is a good measure of obesity in SCI patients.

In order to use BMI as an index for obesity in SCI patients, precise measurement of height is necessary, but
Table 4. Efforts for weight control in spinal cord injury (SCI) patients

\begin{tabular}{cccc}
\hline $\begin{array}{c}\text { Weight } \\
\text { reduction } \\
\text { method }\end{array}$ & $\begin{array}{c}\text { Exercise } \\
\mathbf{( \% )}\end{array}$ & $\begin{array}{c}\text { Diet } \\
\text { modification } \\
\mathbf{( \% )}\end{array}$ & $\begin{array}{c}\text { Medication } \\
\mathbf{( \% )}\end{array}$ \\
\hline $\begin{array}{c}\text { Level of SCI } \\
\text { Paraplegia }\end{array}$ & 40.2 & 48.7 & 4.5 \\
\hline Tetraplegia & 33.1 & 51.8 & 7.9 \\
\hline Type of SCI & & & \\
Complete & 37.9 & 50.4 & 6.3 \\
\hline Incomplete & 36.7 & 48.9 & 5.0 \\
\hline
\end{tabular}

Exercise, diet modification, medication as weight reduction method SCI did not show significant differences by injury level and completeness.

measuring the height in SCI patients is difficult due to their difficulties in standing. In addition, measurement of body weight is also bothersome because the patient needs to measure the weight of their body and the wheelchair together first and then subtract the weight of the wheelchair itself. Therefore, abdominal circumference was measured in this study, and the abdominal obesity of SCI patients was investigated using this measurement. As a result, there was no significant difference of the abdominal obesity rate between the SCI group (29.2\%) and the GP group (27.4\%). Within the SCI group, sex of the subject, whether they had tetraplegia or paraplegia, completeness of injury, cause of injury, and monthly income did not have a significant correlation with abdominal obesity.

Gupta et al. [19] reported that there was no significant difference of the obesity rate between the GP and SCI patients in a study that investigated 408 SCI patients' BMI. Laughton et al. [20] in a study on 77 Canadian SCI patients suggested that the BMI threshold for diagnosing obesity should be lowered for SCI patients because the obesity rate tends to be underestimated if the BMI is used as a standard.

In this study, there was no significant difference in obesity rate between the SCI group and GP group. It can be assumed that increased abdominal fatty tissue did not result in higher abdominal circumference because of the abdominal muscle atrophy in the SCI group. However, Edwards et al. [16] insisted that the visceral fat amount of SCI patients increases $42 \%$ more than the GP as abdominal circumference increases by $1 \mathrm{~cm}$. 


\section{Characteristics of abdominal obesity in $\mathrm{SCl}$ patients}

Dastgiri et al. [21] and Wells et al. [22] reported that the obesity rate increases with age, while obesity rate decreases with increasing monthly income and education level. This study also demonstrated an increasing rate of abdominal obesity with age in both the GP and SCI groups $(\mathrm{p}<0.001$, odds 1.052$)$ and decreasing rate of $a b-$ dominal obesity as education level became higher.

However, in this study, even though the abdominal obesity rate decreased as monthly income increased in the GP group, such a decrease with increase in income was not observed in the SCI group. This may be explained by the fact that age and education level are independent of SCI whereas monthly income can be influenced by the injury itself, leading to interactive effects.

Previous studies reported that paraplegia patients tend to have a higher obesity rate because they can use their upper extremities to eat more food compared to tetraplegia patients $[19,23]$, but there were no significant differences between the two groups in this study. However, this study revealed that most of the Korean SCI patients tend to rely on diet modification for weight control, so this may have reduced the effect of injury level.

\section{Obesity perception of $\mathrm{SCl}$ patients}

Only $48.8 \%$ and $28.8 \%$ of SCI patients measured their body weight and abdominal circumference within the past year, respectively.

Of the subjects that were determined to be an "abdominal obesity patient", $50.0 \%$ of SCI patients (mild obesity $38.1 \%$, severe obesity $11.9 \%$ ) had the perception that they were obese, and $76.7 \%$ of the GP (mild obesity $50.4 \%$, severe obesity $26.3 \%$ ) perceived themselves to be obese. Therefore, SCI patients with abdominal obesity tended to have a lower rate of perceiving themselves as obese compared to persons with abdominal obesity in the GP.

Teixeira et al. [24] investigated the factors that influenced weight control in 136 subjects and reported that subjective perception of one's body type is related with body weight reduction.

So in order to improve the efficacy of intervention for weight reduction such as exercise and diet modification in SCI patients, this study suggests that it is necessary to help subjects correctly recognize their body type.

\section{Efforts for weight reduction in $\mathrm{SCl}$ patients}

For the method of weight reduction, $46.4 \%$ of the SCI group and $47.2 \%$ of the GP group replied they used "exercise"; there was no significant difference between the groups. However, $53.6 \%$ of the SCI group and $37.1 \%$ of the GP group replied "diet modification", significantly showing that the SCI patients tended to modify their diet to lose weight. Especially, paraplegic patients who have the ability to exercise tried to control weight by diet modification, and not by exercise.

Fifty percent of the SCI group replied that they exercise more than 10 minutes to the extent that they have dyspnea for more than 3 times a week, while only $15.2 \%$ of the GP group replied so. But in the survey of the SCI group, wheelchair basketball, swimming, and moving fast with the wheelchair were given as examples, while the survey of the GP group gave running, mountain climbing, cycling, fast swimming, soccer, basketball, jump rope, squash, and tennis as examples. Therefore, it is difficult to infer from these results that SCI patients exercise more than the GP, due to the different types of exercise subjects engaged in between the two groups.

Ginis et al. [25] reported that $49.9 \%$ of SCI patients have leisure time physical activity, and Kim et al. [26] revealed that $96.2 \%$ of Korean SCI patients have leisure time physical activity. But it is not clear whether "wheelchair riding", given as an example of leisure time physical activity, indicates "means of transportation" or "leisure time physical activity". Also, stretching exercises consisted of $26 \%$ of all activities in the study, so it is not simply comparable with our study, because the intensity and type of exercises are different.

Rates of intensive exercise and flexibility exercise did not show significant differences between the tetraplegic and paraplegic patient groups. For resistive exercise, complete tetraplegic patients had a lower rate of exercise compared to the complete paraplegic patients $(\mathrm{p}=0.019)$ and incomplete paraplegic patients $(\mathrm{p}=0.006)$. But even within the complete tetraplegic group, there exists significantly different exercising ability between C5, C6 level injured patients and C7, C8 level injured patients, which indicates this group has low homogeneity. So it is not simply comparable with our study, because the intensity and type of exercises are different.

\section{Limitations}

In this study, abdominal circumference was used as an indicator for abdominal obesity. However, the reference for determining obesity in SCI patients is still not fully es- 
tablished. In addition, the number of days in a week that each subject carried out exercise was investigated, but the information on the type and the intensity of exercise was not investigated in detail. Also, paraplegic patients had their abdominal circumference measured in the sitting position, but tetraplegic patients had the measurement in the position that they were in at the time of the visit by investigators, so the position during the measurement was not consistent in all subjects. And there was no discrimination between subjects who had abdominal stiffness and those who did not, so further studies on the effect of abdominal stiffness on abdominal circumference are necessary.

In conclusion, the obesity rate of SCI persons was not significantly different to that of the GP. However, selfperception of obesity was lower in SCI persons than in the GP, and there were significant differences in socioeconomic factors between the two groups. Therefore, a specific and systematic weight control program for SCI patients is necessary to control abdominal obesity and weight in this group.

\section{CONFLICT OF INTEREST}

No potential conflict of interest relevant to this article was reported.

\section{ACKNOWLEDGMENTS}

This study was supported by general research fund of Seoul National University Bundang Hospital (11-2011005).

\section{REFERENCES}

1. McGinnis JM. The Surgeon General's report on nutrition and health. R I Med J 1988;71:373.

2. Prasad H, Ryan DA, Celzo MF, Stapleton D. Metabolic syndrome: definition and therapeutic implications. Postgrad Med 2012;124:21-30.

3. Ernst ND, Obarzanek E, Clark MB, Briefel RR, Brown $\mathrm{CD}$, Donato K. Cardiovascular health risks related to overweight. J Am Diet Assoc 1997;97(7 Suppl):S47-51.

4. Brown CD, Higgins M, Donato KA, Rohde FC, Garrison $\mathrm{R}$, Obarzanek $\mathrm{E}$, et al. Body mass index and the prevalence of hypertension and dyslipidemia. Obes
Res 2000;8:605-19.

5. Vetter ML, Wadden TA, Lavenberg J, Moore RH, Volger S, Perez JL, et al. Relation of health-related quality of life to metabolic syndrome, obesity, depression and comorbid illnesses. Int J Obes (Lond) 2011;35:108794.

6. Wahman K, Nash MS, Lewis JE, Seiger A, Levi R. Cardiovascular disease risk and the need for prevention after paraplegia determined by conventional multifactorial risk models: the Stockholm spinal cord injury study. J Rehabil Med 2011;43:237-42.

7. Groah SL, Weitzenkamp D, Sett P, Soni B, Savic G. The relationship between neurological level of injury and symptomatic cardiovascular disease risk in the aging spinal injured. Spinal Cord 2001;39:310-7.

8. DeVivo MJ, Krause JS, Lammertse DP. Recent trends in mortality and causes of death among persons with spinal cord injury. Arch Phys Med Rehabil 1999;80:1411-9.

9. Garshick E, Kelley A, Cohen SA, Garrison A, Tun CG, Gagnon D, et al. A prospective assessment of mortality in chronic spinal cord injury. Spinal Cord 2005;43:40816.

10. Orakzai SH, Orakzai RH, Ahmadi N, Agrawal N, Bauman WA, Yee F, et al. Measurement of coronary artery calcification by electron beam computerized tomography in persons with chronic spinal cord injury: evidence for increased atherosclerotic burden. Spinal Cord 2007;45:775-9.

11. Bauman WA, Spungen AM. Disorders of carbohydrate and lipid metabolism in veterans with paraplegia or quadriplegia: a model of premature aging. Metabolism 1994;43:749-56.

12. Lee S, Park HS, Kim SM, Kwon HS, Kim DY, Kim DJ, et al. Cut-off points of waist circumference for defining abdominal obesity in the Korean population. Korean J Obes 2006;15:1-9.

13. Koebnick C, Smith N, Huang K, Martinez MP, Clancy HA, Kushi LH. The prevalence of obesity and obesityrelated health conditions in a large, multiethnic cohort of young adults in California. Ann Epidemiol 2012;22:609-16.

14. Howel D. Trends in the prevalence of abdominal obesity and overweight in English adults (1993-2008). Obesity (Silver Spring) 2012;20:1750-2.

15. McDonald CM, Abresch-Meyer AL, Nelson MD, Wid- 
man LM. Body mass index and body composition measures by dual x-ray absorptiometry in patients aged 10 to 21 years with spinal cord injury. J Spinal Cord Med 2007;30 Suppl 1:S97-104.

16. Edwards LA, Bugaresti JM, Buchholz AC. Visceral adipose tissue and the ratio of visceral to subcutaneous adipose tissue are greater in adults with than in those without spinal cord injury, despite matching waist circumferences. Am J Clin Nutr 2008;87:600-7.

17. Buchholz AC, McGillivray CF, Pencharz PB. The use of bioelectric impedance analysis to measure fluid compartments in subjects with chronic paraplegia. Arch Phys Med Rehabil 2003;84:854-61.

18. Eriks-Hoogland I, Hilfiker R, Baumberger M, Balk S, Stucki G, Perret C. Clinical assessment of obesity in persons with spinal cord injury: validity of waist circumference, body mass index, and anthropometric index. J Spinal Cord Med 2011;34:416-22.

19. Gupta N, White KT, Sandford PR. Body mass index in spinal cord injury: a retrospective study. Spinal Cord 2006;44:92-4.

20. Laughton GE, Buchholz AC, Martin Ginis KA, Goy RE; SHAPE SCI Research Group. Lowering body mass index cutoffs better identifies obese persons with spinal cord injury. Spinal Cord 2009;47:757-62.

21. Dastgiri S, Mahdavi R, TuTunchi H, Faramarzi E. Prev- alence of obesity, food choices and socio-economic status: a cross-sectional study in the north-west of Iran. Public Health Nutr 2006;9:996-1000.

22. Wells JC, Marphatia AA, Cole TJ, McCoy D. Associations of economic and gender inequality with global obesity prevalence: understanding the female excess. Soc Sci Med 2012;75:482-90.

23. Sabour H, Javidan AN, Vafa MR, Shidfar F, Nazari $\mathrm{M}$, Saberi H, et al. Obesity predictors in people with chronic spinal cord injury: an analysis by injury related variables. J Res Med Sci 2011;16:335-9.

24. Teixeira PJ, Going SB, Houtkooper LB, Cussler EC, Metcalfe LL, Blew RM, et al. Exercise motivation, eating, and body image variables as predictors of weight control. Med Sci Sports Exerc 2006;38:179-88.

25. Ginis KA, Arbour-Nicitopoulos KP, Latimer AE, Buchholz AC, Bray SR, Craven BC, et al. Leisure time physical activity in a population-based sample of people with spinal cord injury part II: activity types, intensities, and durations. Arch Phys Med Rehabil 2010;91:729-33.

26. Kim IT, Mun JH, Jun PS, Kim GC, Sim YJ, Jeong HJ. Leisure time physical activity of people with spinal cord injury: mainly with clubs of spinal cord injury patients in Busan-Kyeongnam, Korea. Ann Rehabil Med 2011;35:613-26. 
Appendix 1. Survey for spinal cord injury subjects

1. How many days in a week do you perform exercises for more than 10 minutes which are hard or induce dyspnea? (Examples: wheelchair basketball, swimming, going fast with wheelchair)

(1) Not at all (o question number 2)

(2) 1 day (3) 2 days (4) 3 days (5) 4 days (6) 5 days (7) 6 days (8) 7 days (everyday)

(

1-1. How many minutes in a day did you perform the above exercises?

$$
\text { ( ) hour ( ) minute(s) per a day }
$$

2. How many days in a week do you perform stretching or free gymnastics?
(1) Not at all
(2) 1 day
(3) 2 days
(4) 3 days
(5) 4 days
(6) 5 days or more

3. How many days in a week do you perform resistive exercises such as push-ups, sit-ups, and dumbbell exercise?
(1) Not at all
(2) 1 day
(3) 2 days
(4) 3 days
(5) 4 days
(6) 5 days or more

4. What do you think of your body type now?
(1) Very slim
(2) Slightly slim
(3) Normal
(4) Slightly fat
(5) Very fat

5. Have you ever measured your body weight within the last year?
(1) Yes (go to question number 5-1)
(2) No (go to question number 6)
$5-1$. What is your current body weight? $\mathrm{kg}$ (measurement)

6. Have you ever measured your abdominal circumference within the last year?

(1) Yes (2) No

6-1. What is your current abdominal circumference? $\mathrm{cm}$ (measurement)

(To the first digit under the decimal point, at the level of the umbilicus during expiration)

7. What is your height? $\mathrm{cm}$

8. Do you think your body weight changed in the last year?
(1) Increased more than $3 \mathrm{~kg}$
(2) Decreased more than $3 \mathrm{~kg}$
(3) No change (increased or decreased less than $3 \mathrm{~kg}$ )
(4) Don't know

9. Have you tried to control your body weight by yourself within the last year?
(1) I tried to reduce my body weight (go to question number 10)
(2) I tried to maintain my body weight (go to question number 10)
(3) I tried to increase my body weight (go to question number 11)
(4) I never tried to control my body weight 
10. Check every method that you have tried within the last year to reduce or maintain body weight.

(1) Exercise

(2) Not eating for more than 24 hours

(3) Diet modification

(4) Diet pills without doctor's prescription

(5) Diet pills with doctor's prescription

(6) Oriental (Korean) medicine

(7) Health functional food

(8) One food diet (eating only one type of food such as grape, milk, potato, sweet potato)

(9) Others (Please write specifically $\Rightarrow$

11. What is the most important reason you tried to control your body weight? Check what you think is the most important reason.

(1) To control health problems (Example: hypertension, cardiac diseases)

(2) To become more healthy although there are no significant problems currently.

(3) For balanced body type

(4) Others (Please write specifically $\Rightarrow$ 